Article

\title{
Transient Analysis of Grout Penetration With Time-Dependent Viscosity Inside 3D Fractured Rock Mass by Unified Pipe-Network Method
}

\author{
Zizheng Sun ${ }^{1}$, Xiao Yan ${ }^{2}$, Rentai Liu ${ }^{3}$, Zhenhao $\mathrm{Xu}^{3}$, Shucai $\mathrm{Li}^{3}$ and Yiming Zhang ${ }^{1, *(D)}$ \\ 1 School of Civil and Transportation Engineering, Hebei University of Technology, Tianjin 300401, China; \\ zizheng.sun@hebut.edu.cn \\ 2 State Key Laboratory for Geo-mechanics and Deep Underground Engineering, \\ China University of Mining and Technology, Xuzhou 221116, China; xyan2257@163.com \\ 3 Geotechnical \& Structural Engineering Research Center, Shandong University, Jinan 250061, China; \\ rentailiu@163.com (R.L.); zhenhao_xu@sdu.edu.cn (Z.X.); lishucai@sdu.edu.cn (S.L.) \\ * Correspondence: Yiming.Zhang@hebut.edu.cn; Tel.: +86-022-6043-5940
}

Received: 18 July 2018; Accepted: 13 August 2018; Published: 23 August 2018

\begin{abstract}
Grouting is widely used for mitigating the seepage of underground water and enhancing the stability of fractured rock mass. After injection, the viscosity of the grout gradually increases until solidification. Conventional multifield analysis models ignoring such effects greatly overestimate the penetration region of the grout and the stability of the grouted rock structures. Based on the 3D unified pipe-network method (UPM), we propose a novel numerical model considering the time-dependent viscosity of the grout, therein being a quasi-implicit approach of high efficiency. The proposed model is verified by comparing with analytical results and a time-wise method. Several large-scale 3D examples of fractured rock mass are considered in the numerical studies, demonstrating the effectiveness and robustness of the proposed method. The influence of the time-dependent viscosity, fracture properties, and grouting operation methods are discussed for the grout penetration process.
\end{abstract}

Keywords: grout penetration; transient analysis; time-dependent viscosity; unified pipe-network method

\section{Introduction}

The existence of discontinuous fractures provides paths for underground water, which reduce the mechanical strength and increase the permeability of the rock mass. In engineering practices, sealing the fractured rock mass is a critical issue in large-scale rock engineering projects such as mining, civil, and hydrogeology engineering for avoiding potential water and mud inrush [1,2]. As one of the most effective methods, grouting is a widely used strategy for improving the mechanical properties of rock mass and mitigating groundwater leakages [3-7]. One of the biggest challenges in grouting flow in fractured rock masses is computing the penetration regions of the grout. Because of the complexity of the fracture networks, bare experimental and analytical investigations [8-12] are not sufficient for evaluating their grouting qualities [13-16]. The results achieved by these approaches are mainly suitable for rock masses with a single fracture or regular fracture systems, which cannot reproduce the grouting flow in masses with multiple irregular fractures [17].

For predicting the grouting regions in fracture rock masses, numerical methods are much more flexible and are commonly implemented under the frameworks of extended [18-22]/embedded [23-32]/phase-field [33-42] finite element methods; rigid body based methods [43-49]; and even some sophisticated particle methods and peridynamic-based methods [50-55]. Nevertheless, most of these methods are developed for continuous media such as plain concrete [56-58], which are not 
suitable for highly fractured rock masses when the significant geological features of the fractures are not considered explicitly. Discrete fracture networks (DFNs) are widely used for simulating liquid flows in fractured rock mass. DFN methods can directly model the geometry and hydraulic properties of discrete fractures, being advantageous compared to conventional continuum-oriented models. Two-dimensional DFN methods for simulating the grouting flow in fractured rock mass have been developed. For example, Yang et al. [59] simulated the grout propagation in a vertical section of a DFN in which equivalent permeability tensors for the heterogeneous and anisotropic media are used. Hässler et al. [60], Rahmani [61] and Fidelibus [62] studied the grouting in a two-dimensional structured network of fractures. They assumed a pipe network as an equivalence to a DFN. Pipes are one-dimensional conductors aligned along the fracture planes, and connect the mid-points of two traces [63-65].

The 3D unified pipe-network method (3D UPM) [66-69] is an efficient numerical approach for capturing the energy/mass transport processes in 3D fracture networks. UPM transforms the 3D discontinuous fracture network into a 3D system with intersected artificial 1D pipe segments. From this point of view, UPM is similar to lattice elements approaches (LEM) [70-72], both of which simulate complicate $3 \mathrm{D}$ processes in an equivalent lower-dimensional system. On the other hand, UPM is different from LEM as

- $\quad$ UPM uses pipes for capturing transport processes but ignores mechanical behaviors, while LEM uses trusses for capturing the mechanical behaviors;

- UPM introduces pipes parallel to the fracture planes to capture the transport processes in fractures. On the other hand, in LEM the breakages of trusses represent damage/fractures which originally intersect with the fracture planes, but are not parallel to;

- Unlike LEM, UPM cannot simulate fracture propagations and nucleations, which is suitable for simulating transport processes in naturally highly fractured rock mass.

Most numerical models assumes Darcy's flow and uses heat equation [56-58] for simulating grouting penetration, which is different from models based on computational fluid dynamics and does not trace the grout flow. Hence, only the distributions of pressure are obtained as results. It is impossible to directly account for the time-dependent viscosity. Most methods assume constant viscosity and ignore the solidification processes of the grout after injection. However, the grouting materials for quickly sealing water-bearing fractures in rock masses possess time-dependent viscosities that increase rapidly after injection due to chemical reactions (solidification), such as with silica sol and cement-silicate sodium grout [73-75], which have been proven by experimental investigations [76,77]. To the best of our knowledge, there is limited research on simulating the time-dependent viscosity of grout and its impact on the grouting process in the framework of DFN models.

In this work, we present a novel and simple strategy for accounting for the time-dependent viscosity in 3D UPM, which is a quasi-implicit method and exploits the advantages of UPM. A spatialand time-dependent parameter is introduced for indicating the elapsed time of the grouting flow to reach a specific position from the injection point. With this strategy, the viscosity of the grout will also be updated at every time step, providing results in good agreement with experimental investigations. The remaining parts of the paper are organized as follows: In Section 2, the control equations of the grout are briefly introduced, with corresponding discretized forms under the UPM framework. Then, the strategy for accounting for the time-dependent viscosity of the grouting is prescribed. In Section 3, our novel strategy is verified by comparing with analytical solutions and experimental results given in [77]. In Section 4, the grouting process in the fracture networks is simulated, and the influential factors of the grouting are analyzed. The main influential factors are found to include (i) the material properties of the grout, (ii) the characteristics of the fractures, and (iii) the grout operation method. Finally, the concluding remarks are given in Section 5. 


\section{Methodology}

\subsection{Rheological Models of Grout}

In this paper, we assume single-phase flow in our analysis and consider only the grout flow. The grout penetration depth is estimated by the region with grout pressure higher than or equal to the targeted values. The rheological models of grout are divided into two main categories: Newtonian fluid and Bingham fluid. The linear constitutive model of the Newtonian fluid can be expressed as:

$$
\tau=\mu \gamma
$$

where $\tau$ is the shear stress $(\mathrm{Pa}), \mu$ is the dynamic viscosity $(\mathrm{Pa} \cdot \mathrm{s})$, and $\gamma$ is the shear rate $(1 / \mathrm{s})$. Fluids such as very-fine-grained cement-based grout (silica sol) and bacterial grout (MICP) can be regarded as being of this type [78].

A Bingham fluid is a type of viscoplastic fluid that can only flow at a higher shear stresses. The constitutive model of a Bingham fluid is still linear, and can be expressed as

$$
\tau=\mu \gamma+\tau_{0}
$$

where $\tau_{0}$ is the initial yield stress $(\mathrm{Pa})$. When the water-cement ratio is smaller than 1 , the cement-based grout can be considered as this type [79].

The grout flow in a one-dimensional fracture is assumed to be laminar, steady, and incompressible. Figure $1 \mathrm{a}$ is a schematic illustration of a Newtonian grout flow in a single fracture, where $w$ is the hydraulic aperture $(\mathrm{m}), d x$ is the length of a small control volume in the $x$-direction $(\mathrm{m}), P_{g}$ is the grouting pressure $(\mathrm{Pa})$, and $P_{w}$ is the water pressure $(\mathrm{Pa})$. The average flow velocity of a Newtonian fluid in a fracture can be described using the following equation [3]:

$$
\bar{v}=-\frac{k}{\mu(t)} \frac{\partial p}{\partial x}
$$

where $x$ is the global coordinate for the fracture $(\mathrm{m}), p$ is the grout pressure $(\mathrm{Pa}), \mu(t)$ is the time-varying viscosity $(\mathrm{Pa} \cdot \mathrm{s})$, and $k$ is the fracture intrinsic permeability $\left(\mathrm{m}^{2}\right)$. The grout flow in fractures obeys the Darcy's law, thus the permeability for fractures can be written as $k=w^{2} / 12$.

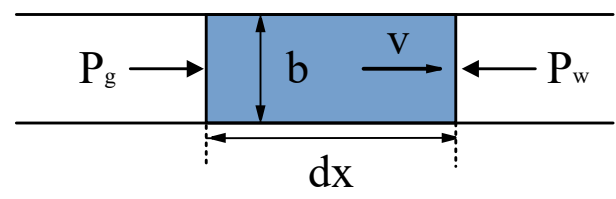

(a)

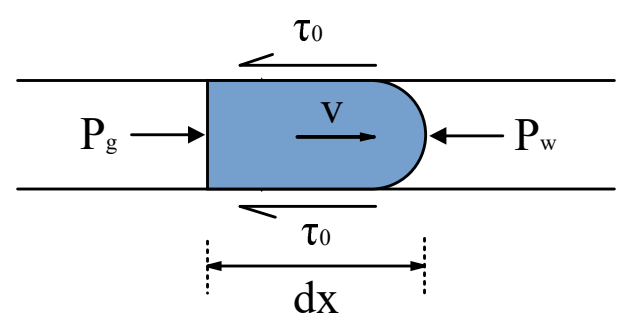

(b)

Figure 1. Schematic illustration of the grout flow in a fracture joint (a) Newtonian grout flow, (b) Bingham grout flow.

Figure $1 \mathrm{~b}$ shows the Bingham grout flow between the parallel plates. Due to the effect of the initial yield stress, the mean velocity of the grout forehead is given:

$$
\left\{\begin{array}{l}
\bar{v}=-\frac{k}{\mu(t)}\left(\frac{\partial p}{\partial x}+\delta\right),\left|\frac{\partial p}{\partial x}\right|>|\delta|, \\
\bar{v}=0, \text { others, }
\end{array}\right.
$$


where $\delta=-\tau_{0} / w$ is the starting pressure gradient. The grout will only flow in the fracture when the pressure gradient is higher than the starting pressure gradient.

\subsection{Unified Pipe-Network Method (UPM) Discrete Model}

In the UPM framework, the energy/mass transport inside the fracture is equivalently considered as energy/mass transport through the artificial pipes along the fracture boundaries. The equivalent hydraulic parameters of the pipes are derived based the unstructured triangular mesh (see Figure 2).
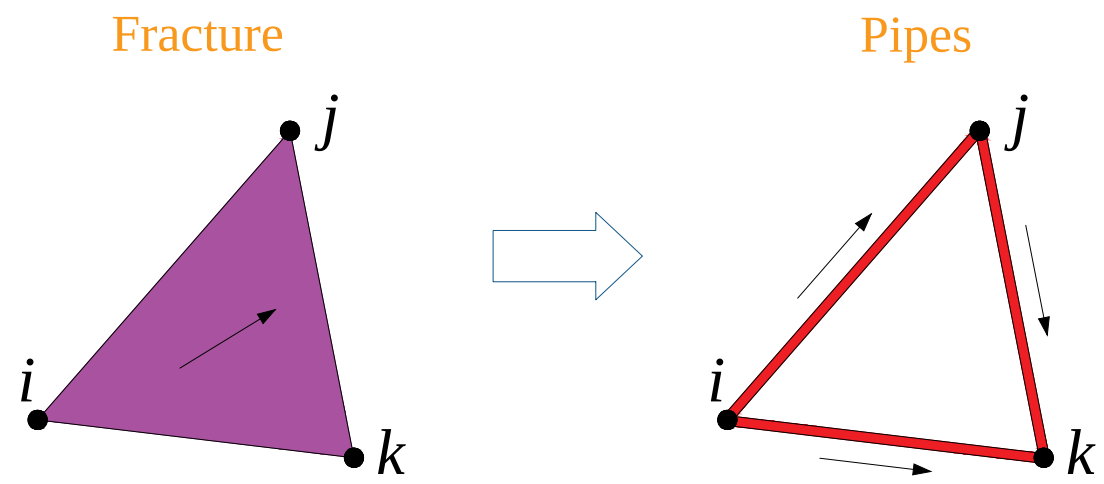

Figure 2. Transformation of the mass transport inside a fracture into the mass transport through artificial pipes on the fracture boundaries (regarding triangular mesh).

Figure 3 shows a triangular fracture with node $i, j, k . o$ is the center point of the triangular fracture and $g, f, h$ are the corresponding three perpendicular feet of $o$ to the edges. The flow in each pipe can be seen as the flow through the line linking the point $o$ and points $g, f, h$. Points $o, g, f, h$ separate the triangle into three polygons as $i f o g, j g o h$, and khof. The areas of these polygons provide information of the control volume of the nodes $i, j, k$ as:

$$
\left\{\begin{array}{l}
V_{i}=1 A_{\text {ifog }} \\
V_{j}=1 A_{\text {jgoh }} \\
V_{k}=1 A_{\text {khof }} .
\end{array}\right.
$$

Based on [66,67], for the pipe $i k$, the fluid flow rate $Q_{i k}\left(\mathrm{~m}^{3} / \mathrm{s}\right)$ shown in Figure 3 can be evaluated as

$$
Q_{i k}=Q \cdot n_{o f}=\int_{l_{o f}} \mathbf{v} \cdot \mathbf{n}_{\mathbf{o f}} d l,
$$

where $\mathbf{n}_{\mathbf{o f}}$ is a unit vector normal to the face $o f$, which can be calculated as:

$$
\mathbf{n}_{\mathbf{o f}}=\frac{1}{l_{i k}}\left[\left(x_{k}-x_{i}\right) \overrightarrow{\mathbf{x}}+\left(y_{k}-y_{i}\right) \overrightarrow{\mathbf{y}}\right]
$$

where $l_{i k}$ is the length of pipe $i k$.

In each fracture triangle element (composed of nodes $i, j$, and $k$ ), the pressure within the triangle mesh can be written as

$$
p(x, y)=\sum N_{m} p_{m}, \quad m=i, j, k,
$$

where $N_{m}$ is the linear shape function, expressed as

$$
N_{m}=\frac{1}{2 A_{i j k}}\left(a_{m}+b_{m} x+c_{m} y\right), \quad m=i, j, k .
$$



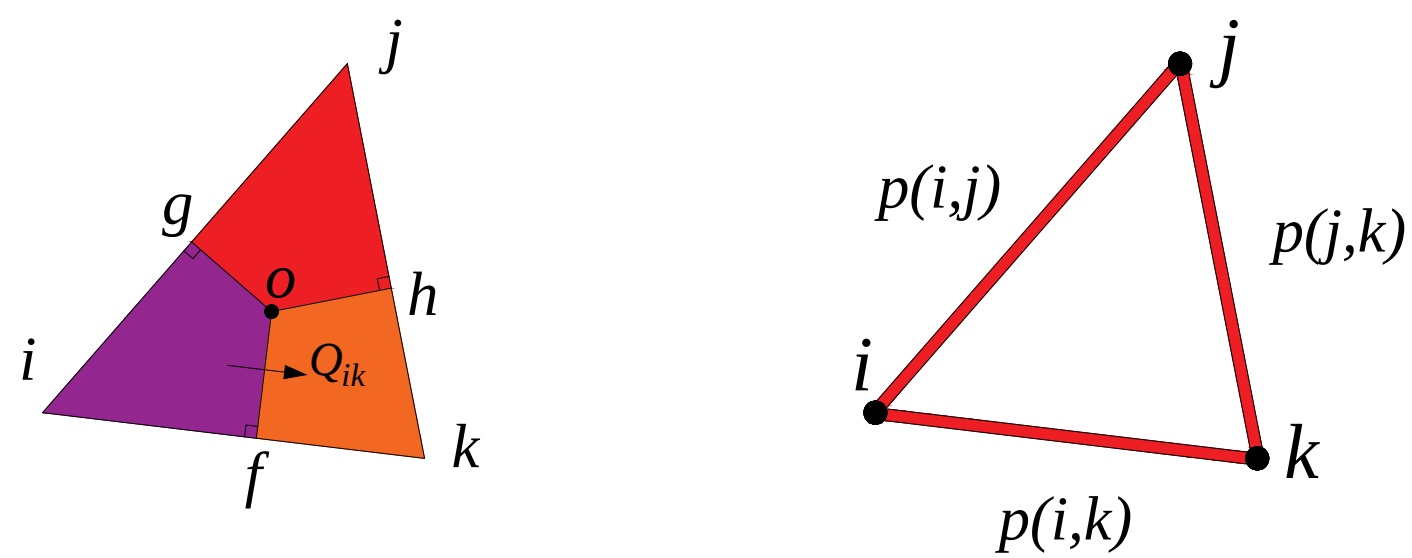

Figure 3. Procedure of pipe equivalence.

The pressure gradient in the triangular domain is calculated as:

$$
\nabla p=\frac{1}{2 A_{i j k}}\left(\left(b_{i} p_{i}+b_{j} p_{j}+b_{k} p_{k}\right) \tilde{\mathbf{x}}+\left(c_{i} p_{i}+c_{j} p_{j}+c_{k} p_{k}\right) \tilde{\mathbf{y}}\right),
$$

where $A_{i j k}$ is the triangle element area. The coefficients $b_{m}$ and $c_{m}$ depend on the coordinates of the three nodes in each triangle element. These coefficients are represented as

$$
\left\{\begin{array} { l } 
{ b _ { i } = y _ { j } - y _ { k } } \\
{ b _ { j } = y _ { k } - y _ { i } } \\
{ b _ { k } = y _ { i } - y _ { j } }
\end{array} \text { and } \left\{\begin{array}{l}
c_{i}=x_{k}-x_{j} \\
c_{j}=x_{i}-x_{k} \\
c_{k}=x_{j}-x_{i}
\end{array}\right.\right.
$$

For the pipe $i k$, the flow rate of Newtonian fluid $\left(Q_{o f}^{N}\right)$ can be expressed as:

$$
Q_{i k}^{N}=\frac{A_{o f} w^{2}}{12 \mu(t)} \frac{\Delta p}{l_{i k}}=\frac{l_{o f} w^{3}}{12 \mu(t)} \frac{\Delta p}{l_{i k}}
$$

where $A_{o f}$ is the cross-sectional area of the face of regarding a $3 \mathrm{D}$ fracture with aperture, $A_{o f}=w l_{o f}$ in this paper (no filling media inside the fracture), with $l_{o f}$ as the length of $o f . l_{i k}$ is the length of pipe $i k$.

Similarly, the flow rate of Bingham fluid $\left(Q_{o f}^{B}\right)$ in pipe $i k$ can be expressed as:

$$
\left\{\begin{array}{l}
Q_{i k}^{B}=\frac{l_{o f} w^{3}}{12 \mu(t)} \frac{\Delta p}{l_{i k}}+\frac{l_{o f} w^{3}}{12 \mu(t)} \delta, \Delta p>0\left|\frac{\Delta p}{l_{i k}}\right|>|\delta|, \\
Q_{i k}^{B}=0, \text { other, }
\end{array}\right.
$$

where the superscripts $N$ and $B$ represent the Newtonian fluid and Bingham fluid, respectively. For the fracture pipe $i k$, the equivalent conductance coefficient $K_{i k}^{f}$ can be expressed as:

$$
K_{i k}^{f}=\frac{l_{o f} w^{3}}{12 l_{i k} \mu(t)}
$$

With this procedure, the whole fracture network can be transformed into a 3D pipe network (see Figure 4) with equivalent mass transport properties. 


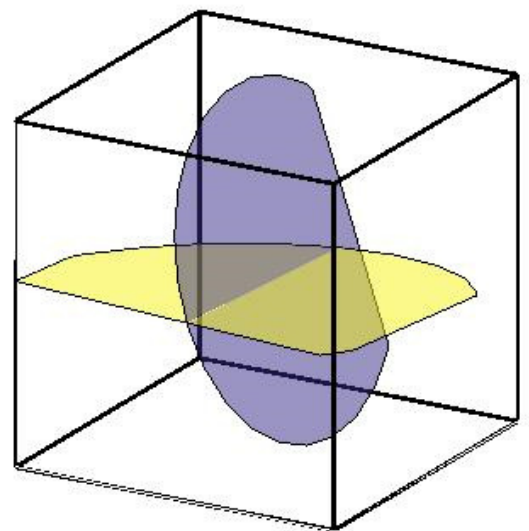

(a)
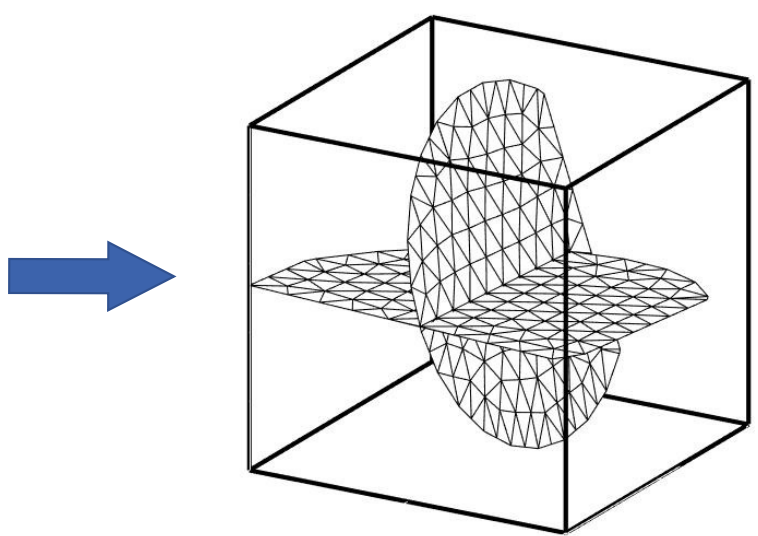

(b)

Figure 4. Transforming a 3D fracture network into an equivalent pipe network: (a) domain with fractures (b) domain with equivalent pipe networks.

With the assumptions of the UPM, in this paper, the grout flow is simulated with a one-dimensional Dupuit-Forchheimer model [80,81] for saturated flow as:

$$
S \frac{\partial h}{\partial t}=-\nabla(-K \nabla h)+q_{s}
$$

where $S$ is the storage coefficient, $h$ is the hydraulic head $(\mathrm{m})$, and $q_{s}$ are the source terms $(\mathrm{m} / \mathrm{s})$.

For each node, the grout flow obeys the law of mass conservation. Therefore, the governing equation in the UPM can be expressed as:

$$
B_{i} \frac{\partial p}{\partial t}+\rho \sum_{i=1}^{n_{i}} Q_{i}=\rho Q_{s i}
$$

where $B_{i}=S V_{i} / g, V_{i}$ is the control volume $\left(\mathrm{m}^{3}\right)$ of node $i$ (see Equation (5)), $\rho$ is the density of the grout $\left(\mathrm{kg} / \mathrm{m}^{3}\right)$, and $\mathrm{g}$ is the gravitational acceleration $\left(\mathrm{m} / \mathrm{s}^{2}\right)$.

\subsection{Considering the Time-Dependent Viscosity in UPM}

In the framework of the UPM, the fractures are equivalently modeled as pipe networks. Points in the considered domain are connected with pipes. For each pipe, the velocity of the grout flow is determined by the pressures of the two nodes. When the pressure distribution is known, the elapsed time for the grout to transport from one point to another can be calculated by the length of the pipe and the velocity of the grout. The velocity of the grout depends on the pressure gradient as well as the viscosity, and the viscosity depends on the elapsed time for the grout to transport in the pipes. Hence, we introduce a new parameter at every node as "the elapsed time for the grout to reach one node from the injection point", denoted as " $\phi$ ". Obviously, $\phi=0$ at the injection points of the grout. For a pipe connecting nodes $i$ and $j$, a simple relationship exists:

$$
\phi_{j}=\phi_{i}+L_{i, j} / v_{i, j},
$$

where $L_{i, j}$ is the length of the pipe. $v_{i, j}$ is the velocity of the grout flow, which is a function of pressure and viscosity at the nodes, as $v\left(\mu_{i}, \mu_{j}, P_{i}, P_{j}\right)$, built based on Equations (3) and (4). Furthermore, 
the viscosity of the grout is a function of $\phi$ (i.e., $\mu=\mu(\phi)$ ). Li et al. [82] presented a power law based on experimental investigations:

$$
\mu(\phi)=k\left(\frac{\phi}{1 \mathrm{~s}}\right)^{n}+\mu_{0}
$$

where $k$ is the flow consistency index $(\mathrm{Pa} \cdot \mathrm{s}), n$ is the flow behavior index, and $\mu_{0}$ is the initial viscosity (Pa-s). In summary, if $P_{i}, P_{j}$, and $\phi_{i}$ are known, $\phi_{j}$ is the only unknown in Equation (17), which can be solved by a standard Newton method. To solve for $\phi$ at time step $t$, a quasi-implicit strategy is used: the pressure distribution of time step $t-1$ is used for implicitly solving $\mu$ at time step $i$. Compared to the analysis with constant viscosity, our method is very efficient, requiring negligible computing efforts.

Here, we give an example of how to calculate $\phi$. Figure 5 a shows a fracture plate consisting of five nodes, and the pressures at the nodes $P_{1} \cdots P_{5}$ are known $\left(P_{1} \cdots P_{5}\right.$ are obtained in the last time step). We assume that node 1 is the injection point and that $\phi_{1}=0\left(\mu_{1}=\mu_{0}\right)$. Nodes 2,3 , and 4 are adjacent nodes of node 1 , and $\phi$ at these three points can be calculated by solving the following equations:

$$
\begin{aligned}
& \phi_{i, 1}=\phi_{1}+L_{i, 1} / v_{i, 1}, \\
& \text { with } \\
& v_{i, 1}=v\left(\mu_{i}, \mu_{1}, P_{i}, P_{1}\right)=-\frac{2 k_{i, 1}}{\mu_{i}+\mu_{1}} \frac{P_{i}-P_{1}}{L_{i, 1}}, \quad i=2,3,4 ;
\end{aligned}
$$

in which $v_{i, 1}$ is obtained based on Equation (3).

Since nodes 2 and 4 only connect to node 1 , their $\phi$ values are only such that $\phi_{2}=\phi_{2,1}$ and $\phi_{4}=\phi_{4,1}$. However, node 3 connects not only to node 1 , but also to nodes 2 and 4 . In other words, three values of $\phi$ exist at node $3, \phi_{3,1}, \phi_{3,2}$, and $\phi_{3,4}$, which are obtained based on the pipes connecting to nodes $(3,1),(3,2)$, and $(3,4)$. Here, we make a direct assumption that $\phi_{3}$ is the minimum value of $\phi_{3,1}$, $\phi_{3,2}$, and $\phi_{3,4}$ (i.e., $\left.\phi_{3}=\min \left(\phi_{3,1}, \phi_{3,2}, \phi_{3,4}\right)\right)$. Similarly, $\phi_{5}=\min \left(\phi_{5,3}, \phi_{5,4}\right)$ - see Figure $5 \mathrm{~b}$. With this method, the $\phi$ values at each node are obtained sequentially from the injection points.

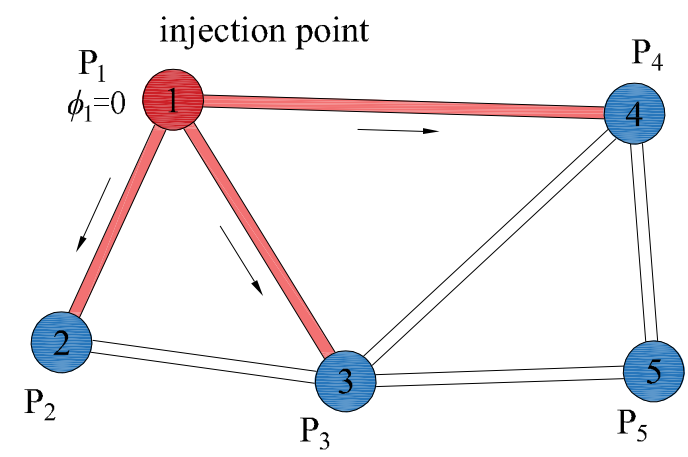

(a)

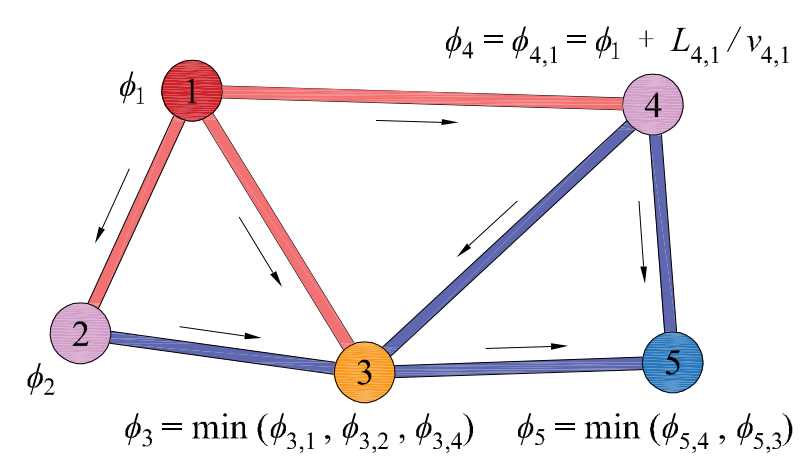

(b)

Figure 5. Calculation of $\phi$ in the unified pipe-network method (UPM) model: (a) calculate $\phi$ from injection point, (b) determining the values of $\phi$ from one node to another.

\section{Model Verification}

In this section, a rectangular fracture $(10 \mathrm{~m} \times 10 \mathrm{~m})$ in a cube with dimensions $10 \mathrm{~m} \times 10 \mathrm{~m} \times$ $10 \mathrm{~m}$ is used for verification. The grout was injected into a single fracture with an injection hole (see Figure 6). Two cases were considered: (i) comparing our results to the analytical solutions and (ii) comparing our results to the experimental results given in [77], considering time-dependent viscosities. With UPM, a self-developed mesh generator [83] is adopted to generate triangle elements for the fractures. The parameters employed in the simulation are listed in Table 1. 


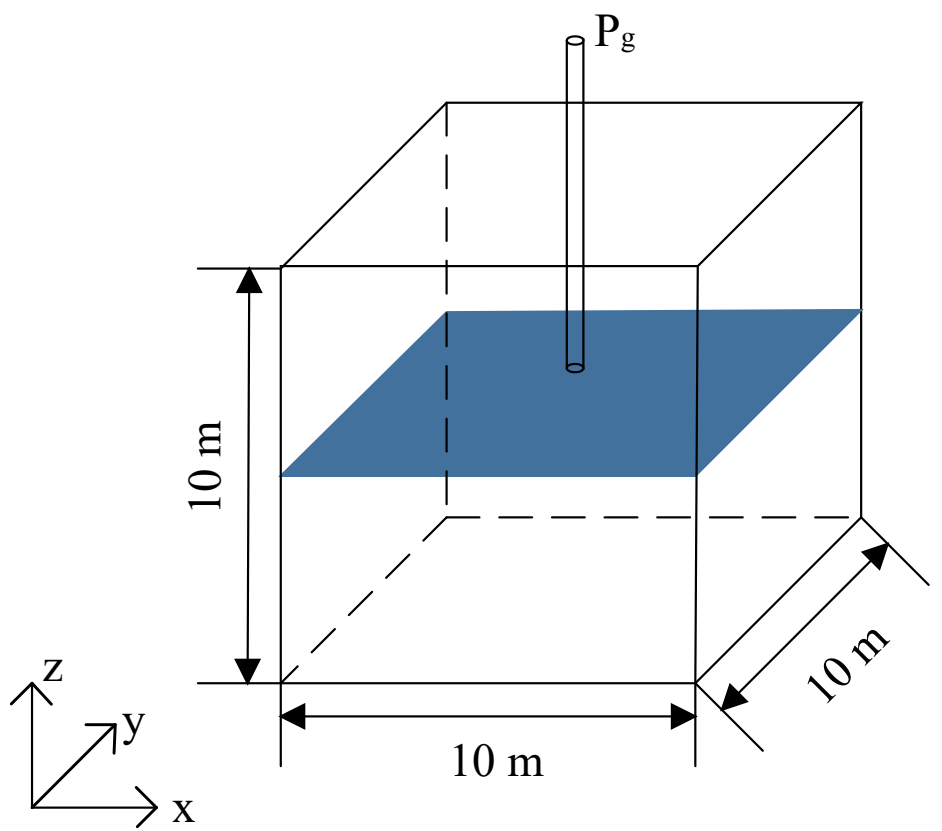

Figure 6. Three-dimensional model with a fracture for verification.

Table 1. Parameters for verification simulation.

\begin{tabular}{llll}
\hline Parameters & Symbol & Unit & Value \\
\hline Grout injection pressure & $p$ & $\mathrm{~Pa}$ & 30,000 \\
Pore pressure of fracture & $p_{0}$ & $\mathrm{~Pa}$ & 0 \\
Grout density & $\rho$ & $\mathrm{kg} / \mathrm{m}^{3}$ & 1400 \\
Yield stress & $\tau_{0}$ & $\mathrm{~Pa}$ & 1.0 \\
Initial grout viscosity & $\mu_{0}$ & $\mathrm{~Pa} \cdot \mathrm{s}$ & 0.04 \\
Flow consistency index & $k$ & $\mathrm{~Pa} \cdot \mathrm{s}$ & 0.003182 \\
Flow behavior index & $n$ & - & 2.23 \\
Fracture aperture & $b$ & $\mathrm{~m}$ & 0.005 \\
Storage coefficient & $S$ & {$[-]$} & 1.4 \\
Gravitational acceleration & $g$ & $\mathrm{~m} / \mathrm{s}^{2}$ & 9.8 \\
\hline
\end{tabular}

\subsection{Verifying the Rheological Models}

In this subsection, we first verify the rheological models, where the viscosity of the grout is considered to be a constant value $\mu_{0}$. The analytical solutions for Newtonian fluid and Bingham fluid have been proposed by Funehag [3] and Gustanafson [84], which are taken for verification.

Funehag [3] calculated the grout penetration for a Newtonian fluid with constant viscosity $\mu_{0}$ as:

$$
I=b \sqrt{\frac{\Delta p t}{6 \mu_{0}}}
$$

where $\Delta p$ is the difference between the injection pressure and initial pore pressure, and $t$ is the flow time.

Gustafson [84] proposed a solution for grout penetration distance $(I)$ and penetration time $(t)$ :

$$
\begin{gathered}
I=I_{D} \cdot I_{\max }, \\
t=t_{D} \cdot t_{0}, \\
I_{D}=\sqrt{\theta^{2}+4 \theta}-\theta,
\end{gathered}
$$




$$
\begin{aligned}
& t_{0}=\frac{6 \Delta p \cdot \mu_{0}}{\tau_{0}^{2}}, \\
& I_{\max }=\frac{\Delta p b}{2 \tau_{0}},
\end{aligned}
$$

where $t_{D}$ and $I_{D}$ are relative penetration time and relative penetration length, respectively, $t_{0}$ is the characteristic grouting time, $I_{\max }$ is the maximum grout penetration, and $\theta$ is a ratio influenced by $t_{D}$. However, the ratio is different for one-dimensional flow and two-dimensional flow:

$$
\begin{aligned}
& \theta=\frac{t_{D}}{2\left(0.6+t_{D}\right)} \quad 1 D, \\
& \theta=\frac{t_{D}}{2\left(3+t_{D}\right)} \quad 2 D \text {. }
\end{aligned}
$$

As shown in Figure 7, the grout penetration length along the injection hole obtained by the UPM simulation was consistent with the analytical results at each time step, indicating the effectiveness of our rheological models of grout.

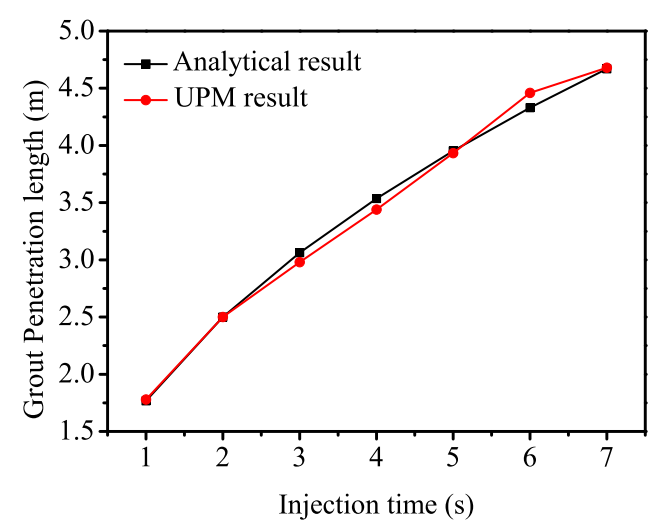

(a)

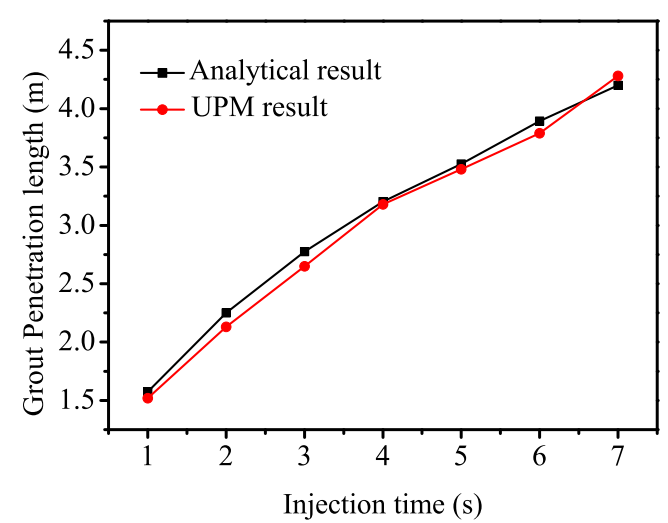

(b)

Figure 7. Comparison of the UPM model with the analytical solutions: (a) Newtonian fluid, (b) Bingham fluid.

\subsection{Transient Flow Considering the Time-Dependent Viscosity of Grout}

Zhang et al. [77] experimentally investigated the grout penetration length of a type of grout with time-dependent viscosity. The experiments were reproduced with our model. The total simulation time was $60 \mathrm{~s}$, and the viscosity of grout ultimately reached $29.4 \mathrm{~Pa} \cdot \mathrm{s}$. Because our strategy is quasi-implicit and the pressure distributions at the last time step were used for calculating the distributions of $\phi$ and $\mu$ in this step. We attempted different time intervals $\Delta t$ for sensitivity analysis. As shown in Figure 8 , comparisons between our results and the experimental results indicated that the results were not sensitive to the selection of $\Delta t$ when $\Delta t \leq 0.05 \mathrm{~s}$. Furthermore, we also tested the influences of UPM discretization. As shown in Figure 9, a total grid number larger than 10,000 assured the reliability of the results.

Figure 10 shows the comparisons of the grouting pressure distribution between our results and the experimental results at different times, with $\Delta t=0.05 \mathrm{~s}$ and a grid number equal to 15,514 . Generally, our results were in agreement with the experimental results, indicating that the proposed model was capable of simulating grout flows with time-dependent viscosities. 


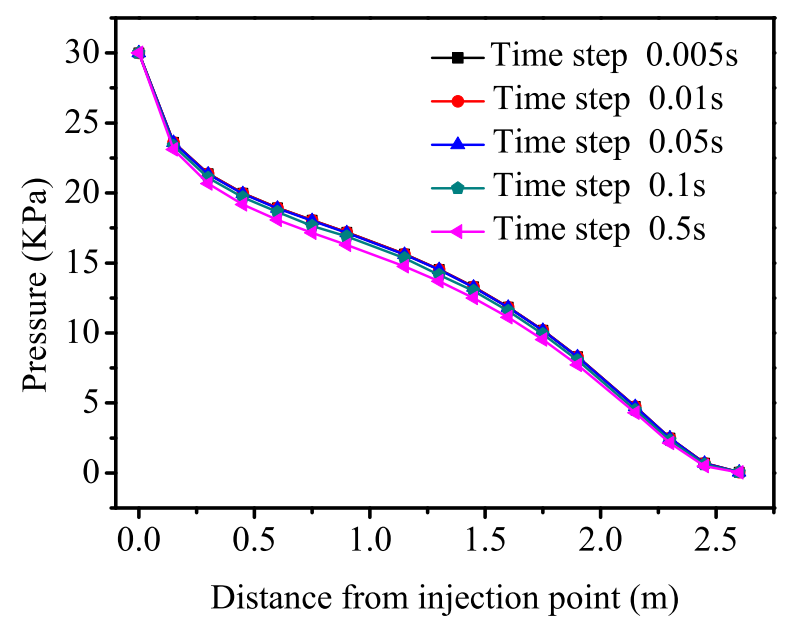

Figure 8. The influence of the time step on the UPM results.

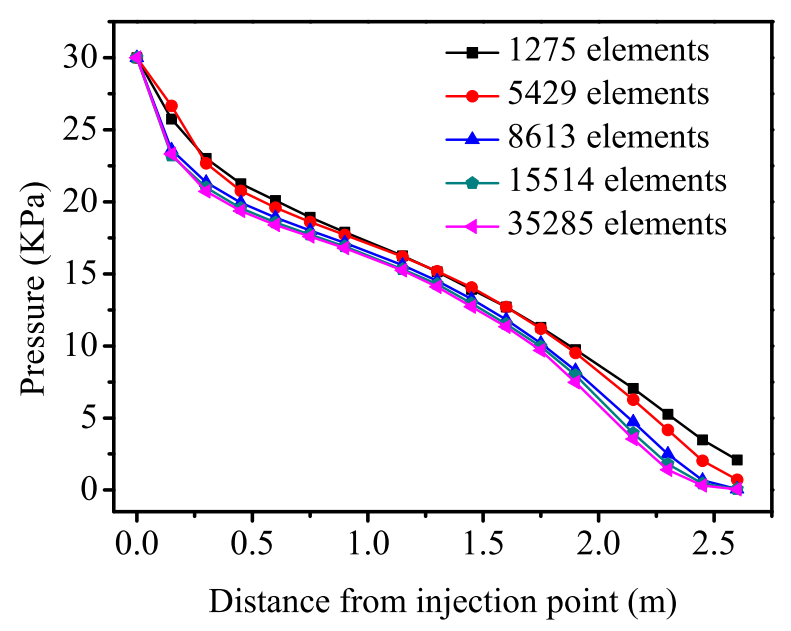

Figure 9. The influence of the grid density on the UPM results.

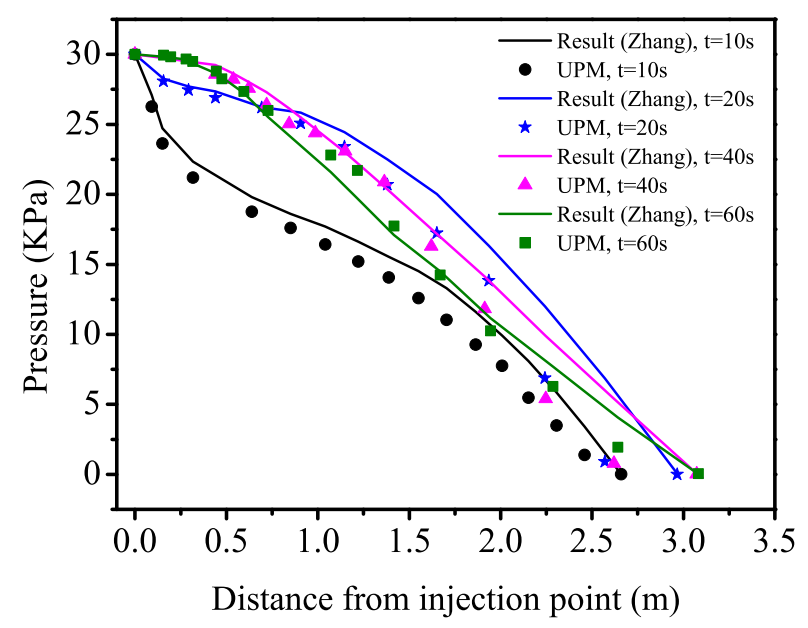

Figure 10. Comparison of the UPM model with results obtained by Zhang [77]. 


\section{Application in Simulating Grouting Process in Rock Mass with Fracture Networks}

The UPM was coded with $\mathrm{C}++$, and all the cases in this section were calculated within $2 \mathrm{~h}$ on a normal desktop. Parametric studies were performed to determine the influences of various parameters, including (i) the material properties of the grout (viscosity), (ii) the characteristics of the fractures (number, aperture, and roughness), and (iii) the grout operation method (the grout pressure, the number of boreholes, and the arrangement of the boreholes) on grout penetration in fractured rock masses.

\subsection{The Influence of Viscosity}

The commonly used quick-setting slurry has two components: cement and sodium silicate slurries. The viscosity function $\mu(\phi)$ depends on the ratio of cement slurry to sodium silicate slurry (C:S). According to the experimental results provided in [85], when C:S $=1$, the flow consistency index $(k)$ and flow behavior index $(n)$ are $0.003182 \mathrm{~Pa} \cdot \mathrm{s}$ and 2.23 , respectively, while they are $0.0008427 \mathrm{~Pa} \cdot \mathrm{s}$ and 2.694 when C:S $=2$ (see Figure 11). The other parameters were considered to be the same as listed in Table 1.

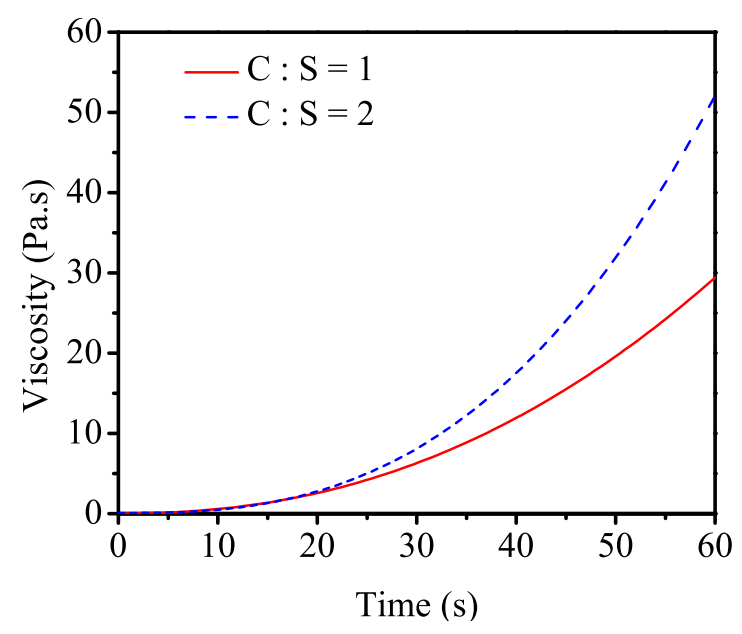

Figure 11. Grout viscosity with time. Reference [77].

Figure 12 shows the pressure distributions for a constant viscosity $\left(\mu=\mu_{0}\right)$ and time-dependent viscosity with varying C:S. The results indicate that assuming a constant viscosity greatly overestimated the penetration length of the grout, and the grout flow lasted for a long time. In the cases with a time-dependent viscosity, on the other hand, the grout flow almost stopped after $30 \mathrm{~s}$. 
Time $=10 \mathrm{~s}$
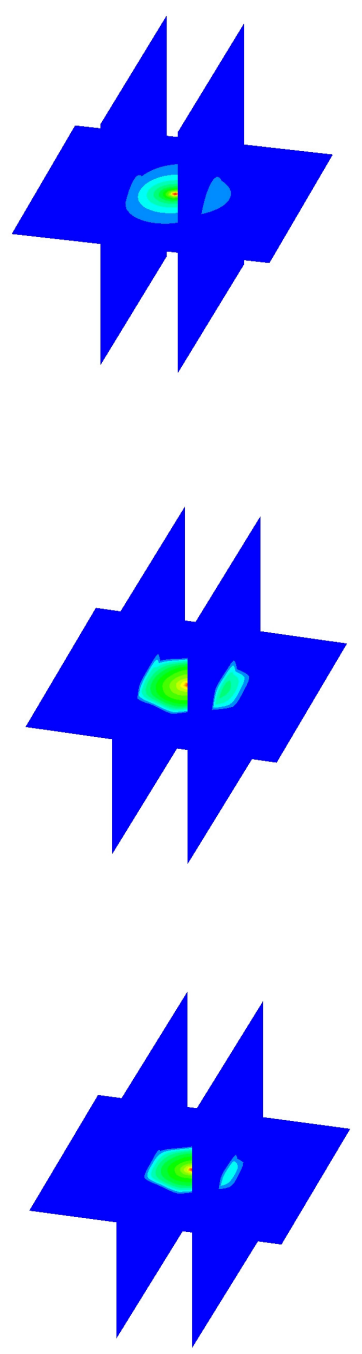

Time $=30 \mathrm{~s}$

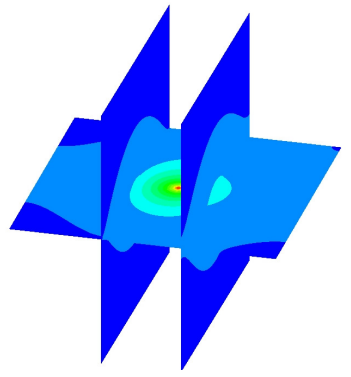

(a) Constant viscosity

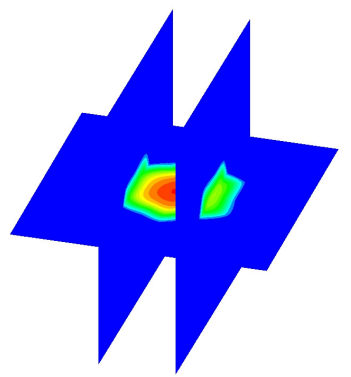

(b) $\mathrm{C}: \mathrm{S}=1$
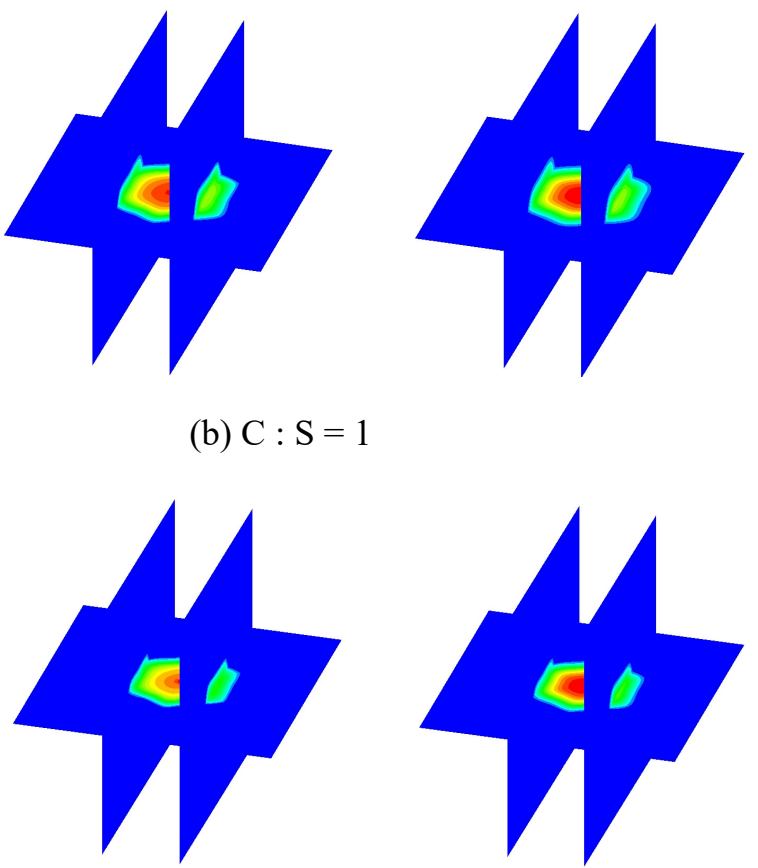

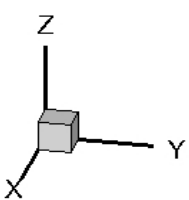

Pressure

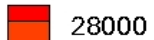

26000

24000

22000

20000

18000

16000

14000

12000

10000

8000

6000

4000

2000

(c) $\mathrm{C}: \mathrm{S}=2$

Figure 12. Distribution of pressure at different simulation times.

\subsection{The Influence of Fractures and Grout Operation Method}

We generated fracture networks to analyze the influences of the fractures on grout penetration with the same cube model size of $10 \mathrm{~m} \times 10 \mathrm{~m} \times 10 \mathrm{~m}$. Two sets of elliptical fractures were generated by a random function with the parameters listed in Table 2. For each fracture, its center coordinate followed a uniform distribution, and the major and minor axes followed a logarithmic distribution. The Fisher coefficient was 22. The configuration of the random fractures and their mesh are illustrated in Figure 13. The red line represents the borehole through the fractured rock. In the model, there were 7088 nodes and 13,210 triangle elements in total. The grout parameters were the same as those listed in Table 1 . The grout was injected through the borehole with an injection pressure of $30 \mathrm{kPa}$. The pressure distributions are shown in Figure 14, therein indicating that the pressure distributions became stable after $90 \mathrm{~s}$. 
Table 2. Parameters adopted for the generation of the fracture models.

\begin{tabular}{|c|c|c|c|c|c|c|}
\hline \multirow{2}{*}{$\frac{\text { Group }}{1}$} & \multirow{2}{*}{$\begin{array}{c}\text { Fracture Number } \\
10\end{array}$} & \multicolumn{2}{|c|}{ Mean Length (m) } & \multirow{2}{*}{$\frac{\text { St Dev }}{2}$} & \multirow{2}{*}{$\frac{\text { Dip Angle (Degree) }}{16}$} & \multirow{2}{*}{$\frac{\text { Dip Direction (Degree) }}{40}$} \\
\hline & & $x$-axis & 5 & & & \\
\hline & & $y$-axis & 3 & 2 & & \\
\hline \multirow[t]{2}{*}{2} & 10 & $x$-axis & 3 & 2 & 56 & 256 \\
\hline & & $y$-axis & 3 & 2 & & \\
\hline
\end{tabular}

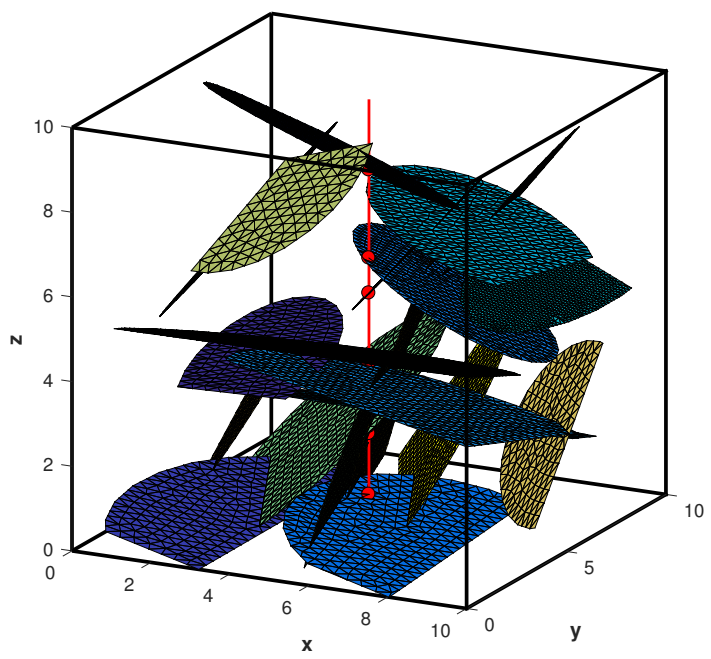

Figure 13. The fracture grid model.

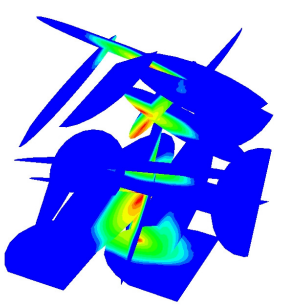

$\mathrm{T}=10 \mathrm{~s}$

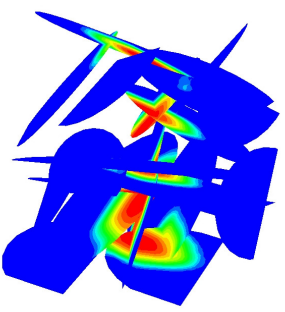

$\mathrm{T}=60 \mathrm{~s}$

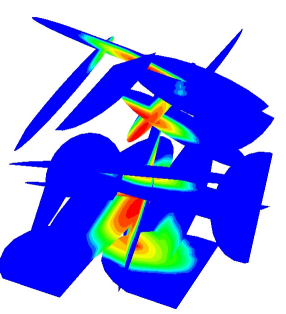

$\mathrm{T}=20 \mathrm{~s}$

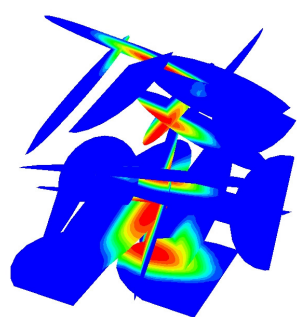

$\mathrm{T}=90 \mathrm{~s}$

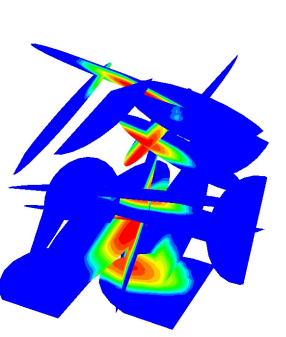

$\mathrm{T}=30 \mathrm{~s}$

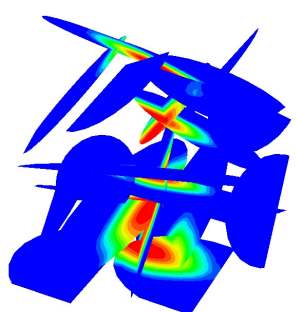

$\mathrm{T}=120 \mathrm{~s}$

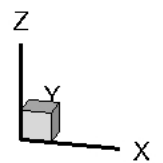

Figure 14. Grout flow process.

Here, we define the grout filling rate as the ratio between the area of grout-filled fractures and the total fracture area. Figure 15 shows the influences of a uniform aperture and joint roughness coefficient (JRC) [86] on the grout filling rate, indicating that the grout filling rate increased with increasing 
joint aperture and decreased with increasing JRC. The influence of JRC on intrinsic permeability was considered by an empirical equation given in [47].
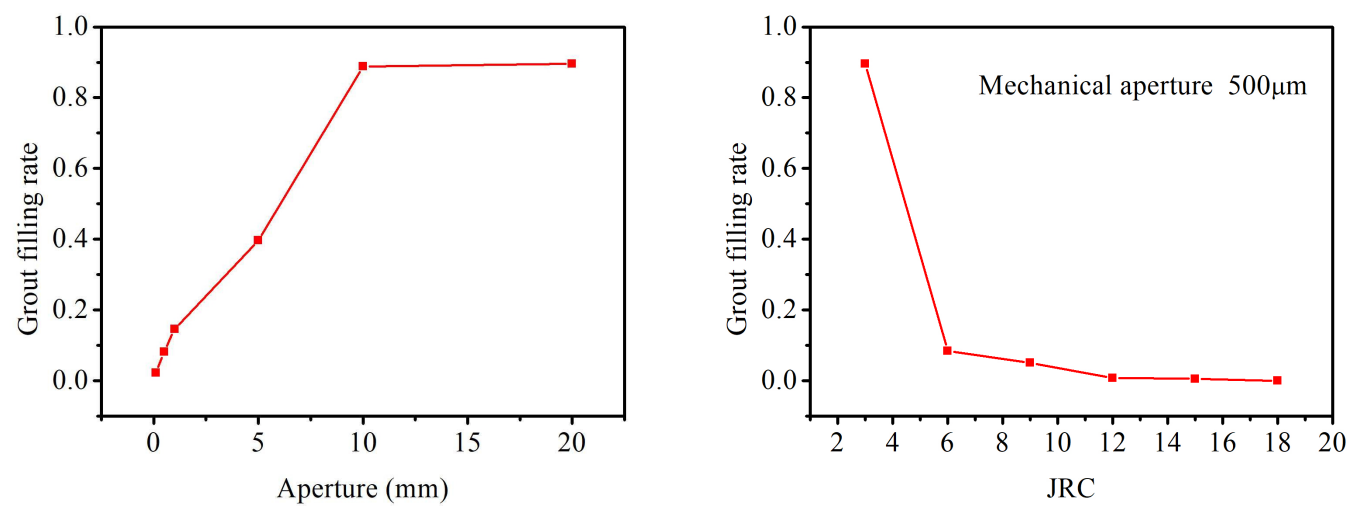

Figure 15. Sensitivity analyses with respect to the fracture aperture and joint roughness. (JRC: joint roughness coefficient.)

Furthermore, we tested different grout operation methods. Figure 16 shows the influences of the grout pressure for a single borehole, and Figure 16 shows the influences of the borehole number at the same injection pressure of $30 \mathrm{kPa}$, indicating that the grout filling rate was increased by increasing either the injection pressure or the number of boreholes.
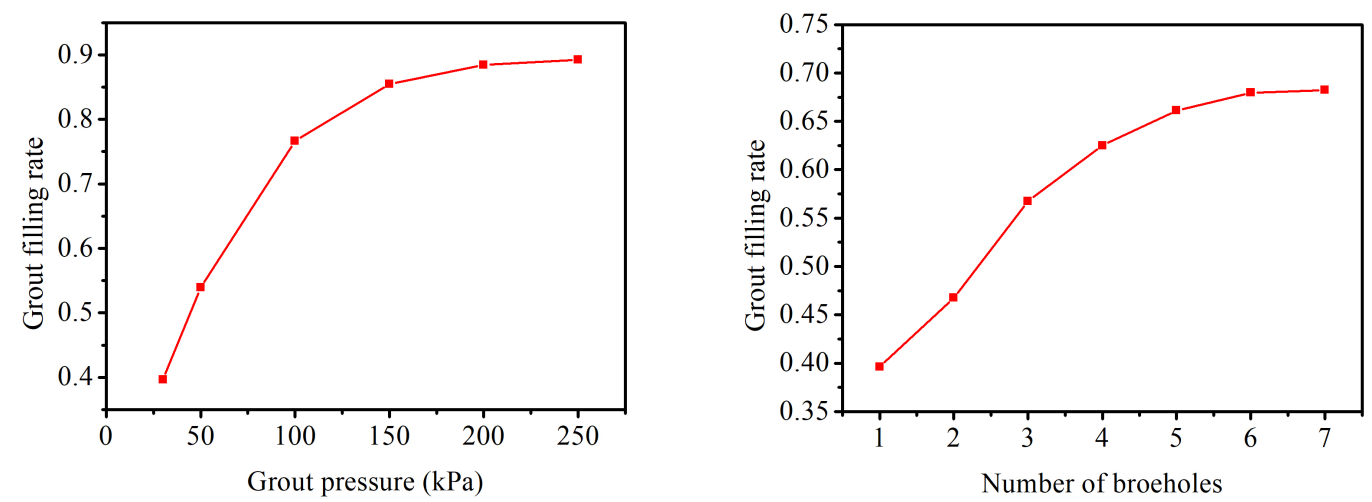

Figure 16. Sensitivity analyses with respect to the grout pressure and the number of boreholes.

\section{Conclusions}

In this study, a three-dimensional numerical model based on the UPM is developed for modeling the transient grout penetration in fractured networks. Rheological models of grout, including Newtonian and Bingham fluids, are considered. A novel quasi-implicit method is presented to account for the time-dependent viscosity of grout, therein calculating the elapsed time $\phi$ of the grout to reach specific positions from the injection points. By comparison to analytical and experimental results, the new model is validated. Finally, parametric and case studies are presented regarding a complicated 3D fractured rock mass with boreholes. All the results evidence the effectiveness of our model, which estimates the penetration regions and time for the stabilization of grout with a time-dependent viscosity. 
Author Contributions: Conceptualization, Y.Z. and X.Y.; Methodology, X.Y. and Y.Z.; Software, Z.S., X.Y. and Z.X.; Validation, R.L., S.L. and X.Y.; Formal Analysis, Z.S. and Y.Z.; Investigation, Z.S.; Resources, Y.Z.; Data Curation, Z.S., S.L. and X.Y.; Writing-Original Draft Preparation, X.Y. and Y.Z.; Writing-Review \& Editing, Z.S. and Y.Z.; Visualization, X.Y.; Supervision, Y.Z.; Project Administration, Y.Z.; Funding Acquisition, Z.S.

Funding: Hebei key research and development program, 18216110D.

Conflicts of Interest: The authors declare no conflict of interest.

\section{Abbreviations}

The following abbreviations are used in this manuscript:

UPM Unified Pipe-Network Method

LEM Lattice Elements Method

\section{References}

1. Mohajerani, S.; Baghbanan, A.; Wang, G.; Forouhandeh, S. An efficient algorithm for simulating grout propagation in 2d discrete fracture networks. Int. J. Rock Mech. Min. Sci. 2017, 98, 67-77. [CrossRef]

2. Jeannin, P.; Malard, A.; Rickerl, D.; Weber, E. Assessing karst-hydraulic hazards in tunneling: the brunnmühle spring system bernese jura, switzerland. Environ. Earth Sci. 2015, 74, 7655-7670. [CrossRef]

3. Funehag, J.; Gustafson, G. Design of grouting with silica sol in hard rock-New methods for calculation of penetration length, Part I. Tunn. Undergr. Space Technol. 2008, 23, 1-8. [CrossRef]

4. Bezuijen, A.; Grotenhuis, R.T.; van Tol, A.; Bosch, J.; Haasnoot, J. Analytical model for fracture grouting in sand. J. Geotech. Geoenviron. Eng. 2010, 137, 611-620. [CrossRef]

5. Hernqvist, L.; Fransson, Å.; Gustafson, G.; Emmelin, A.; Eriksson, M.; Stille, H. Analyses of the grouting results for a section of the apse tunnel at äspö hard rock laboratory. Int. J. Rock Mech. Min. Sci. 2009, 46, 439-449. [CrossRef]

6. Lisa, H.; Christian, B.; Åsa, F.; Gunnar, G.; Johan, F. A hard rock tunnel case study: Characterization of the water-bearing fracture system for tunnel grouting. Tunn. Undergr. Space Technol. 2012, 30, 132-144. [CrossRef]

7. Seo, H.; Choi, H.; Lee, I. Numerical and experimental investigation of pillar reinforcement with pressurized grouting and pre-stress. Tunn. Undergr. Space Technol. 2016, 54, 135-144. [CrossRef]

8. Gustafson, G.; Stille, H. Prediction of groutability from grout properties and hydrogeological data. Tunn. Undergr. Space Technol. 1996, 11, 325-332. [CrossRef]

9. Amadei, B.; Savage, W. An analytical solution for transient flow of bingham viscoplastic materials in rock fractures. Int. J. Rock Mech. Min. Sci. 2001, 38, 285-296. [CrossRef]

10. Xu, Y.; Peng, W.H. Research on multiple holes grouting of fractured rock Mass. Appl. Mech. Mater. 2013, 256, 547-551. [CrossRef]

11. Foyo, A.; Sánchez, M.A.; Tomillo, C. A proposal for a secondary permeability index obtained from water pressure tests in dam foundations. Eng. Geol. 2005, 77, 69-82. [CrossRef]

12. Stille, H.; Gustafson, G.; Hassler, L. Application of new theories and technology for grouting of dams and foundations on rock. Geotech. Geol. Eng. 2012, 30, 603-624. [CrossRef]

13. Brantberger, M.; Stille, H.; Eriksson, M. Controlling grout spreading in tunnel grouting: Analyses and developments of the gin-method. Tunn. Undergr. Space Technol. 2000, 15, 343-352. [CrossRef]

14. Axelsson, M.; Gustafson, G. A robust method to determine the shear strength of cement-based injection grouts in the field. Tunn. Undergr. Space Technol. 2006, 21, 499-503. [CrossRef]

15. Draganović, A.; Stille, H. Filtration and penetrability of cement-based grout: Study performed with a short slot. Tunn. Undergr. Space Technol. 2011, 26, 548-559. [CrossRef]

16. Lee, J.; Bang, C.; Mok, Y.; Joh, S. Numerical and experimental analysis of penetration grouting in jointed rock masses. Int. J. Rock Mech. Min. Sci. 2000, 37, 1027-1037. [CrossRef]

17. Neuman, S.P. Trends, prospects and challenges in quantifying flow and transport through fractured rocks. Hydrogeol. J. 2005, 13, 124-147. [CrossRef]

18. Moës, N.; Bolbow, J.; Belytschko, T. A finite element method for crack growth without remeshing. Int. J. Numer. Methods Eng. 1999, 46, 131-150. [CrossRef] 
19. Moës, N.; Belytschko, T. Extended finite element method for cohesive crack growth. Eng. Fract. Mech. 2002, 69, 813-833. [CrossRef]

20. Song, J.-H.; Areias, P.; Belytschko, T. A method for dynamic crack and shear band propagation with phantom nodes. Int. J. Numer. Methods Eng. 2006, 67, 868-893. [CrossRef]

21. Areias, P.; Song, J.-H.; Belytschko, T. Analysis of fracture in thin shells by overlapping paired elements. Comput. Methods Appl. Mech. Eng. 2006, 195, 41-43. [CrossRef]

22. Wu, J.-Y.; Li, F.-B. An improved stable XFEM (Is-XFEM) with a novel enrichment function for the computational modeling of cohesive cracks. Comput. Methods Appl. Mech. Eng. 2015, 295, 77-107. [CrossRef]

23. Simo, J.; Oliver, J.; Armero, F. An analysis of strong discontinuities induced by strain-softening in rate-independent inelastic solids. Comput. Mech. 1993, 12, 277-296. [CrossRef]

24. Saloustros, S.; Pelà, L.; Cervera, M.; Roca, P. Finite element modelling of internal and multiple localized cracks. Comput. Mech. 2017, 59, 299-316. [CrossRef]

25. Saloustros, S.; Cervera, M.; Pelà, L. Tracking multi-directional intersecting cracks in numerical modelling of masonry shear walls under cyclic loading. Meccanica 2018, 53, 1757-1776. [CrossRef]

26. Saloustros, S.; Cervera, M.; Pelà, L. Challenges, tools and applications of tracking algorithms in the numerical modelling of cracks in concrete and masonry structures. Arch. Comput. Methods Eng. 2018. [CrossRef]

27. Nikolić, M.; Ibrahimbegovic, A.; Miscevic, P. Discrete element model for the analysis of fluid-saturated fractured poro-plastic medium based on sharp crack representation with embedded strong discontinuities. Comput. Methods Appl. Mech. Eng. 2016, 298, 407-427. [CrossRef]

28. Nikolić, M.; Ibrahimbegovic, A.; Miscevic, P. Brittle and ductile failure of rocks: Embedded discontinuity approach for representing mode i and mode ii failure mechanisms. Int. J. Numer. Methods Eng. 2015, 102, 1507-1526. [CrossRef]

29. Nikolić, M.; Ibrahimbegovic, A. Rock mechanics model capable of representing initial heterogeneities and full set of 3d failure mechanisms. Comput. Methods Appl. Mech. Eng. 2015, 290, 209-227. [CrossRef]

30. Zhang, Y.; Lackner, R.; Zeiml, M.; Mang, H. Strong discontinuity embedded approach with standard SOS formulation: Element formulation, energy-based crack-tracking strategy, and validations. Comput. Methods Appl. Mech. Eng. 2015, 287, 335-366. [CrossRef]

31. Zhang, Y.; Zhuang, X. Cracking elements: A self-propagating strong discontinuity embedded approach for quasi-brittle fracture. Finite Elem. Anal. Des. 2018, 144, 84-100. [CrossRef]

32. Zhang, Y.; Zhuang, X. A softening-healing law for self-healing quasi-brittle materials: analyzing with strong discontinuity embedded approach. Eng. Fract. Mech. 2018, 192, 290-306. [CrossRef]

33. Zhou, S.; Zhuang, X.; Zhu, H.; Rabczuk, T. Phase field modelling of crack propagation, branching and coalescence in rocks. Theor. Appl. Fract. Mech. 2018, 96, 174-192. [CrossRef]

34. Wu, J.-Y.; Nguyen, V.-P. A length scale insensitive phase-field damage model for brittle fracture. J. Mech. Phys. Solids 2018, 119, 20-42. [CrossRef]

35. Wu, J.-Y. Robust numerical implementation of non-standard phase-field damage models for failure in solids article. Comput. Methods Appl. Mech. Eng. 2018, 340, 767-797. [CrossRef]

36. Zhou, S.; Rabczuk, T.; Zhuang, X. Phase field modeling of quasi-static and dynamic crack propagation: Comsol implementation and case studies. Adv. Eng. Softw. 2018, 122, 31-49. [CrossRef]

37. Zhou, S.; Zhuang, X.; Rabczuk, T. A phase-field modeling approach of fracture propagation in poroelastic media. Eng. Geol. 2018, 240, 189-203. [CrossRef]

38. Areias, P.; Reinoso, J.; Camanho, P.; César de Sá, J.; Rabczuk, T. Effective 2d and 3d crack propagation with local mesh refinement and the screened poisson equation. Eng. Fract. Mech. 2018, 189, 339-360. [CrossRef]

39. Areias, P.; Msekh, M.; Rabczuk, T. Damage and fracture algorithm using the screened Poisson equation and local remeshing. Eng. Fract. Mech. 2016, 158, 116-143. [CrossRef]

40. Areias, P.; Rabczuk, T.; Msekh, M. Phase-field analysis of finite-strain plates and shells including element subdivision. Comput. Methods Appl. Mech. Eng. 2016, 312, 322-350. [CrossRef]

41. Areias, P.; Rabczuk, T.; Dias-da-Costa, D. Element-wise fracture algorithm based on rotation of edges. Eng. Fract. Mech. 2013, 110, 113-137. [CrossRef]

42. Areias, P.; Rabczuk, T. Finite strain fracture of plates and shells with configurational forces and edge rotations. Int. J. Numer. Methods Eng. 2013, 94, 1099-1122. [CrossRef]

43. Zhang, Y. Multi-slicing strategy for the three-dimensional discontinuity layout optimization (3D DLO). Int. J. Numer. Anal. Methods Geomech. 2017, 41, 488-507. [CrossRef] [PubMed] 
44. Zhang, Y.; Zhuang, X. Stability analysis of shotcrete supported crown of NATM tunnels with discontinuity layout optimization. Int. J. Numer. Anal. Methods Geomech. 2018, 42, 1199-1216. [CrossRef]

45. Min, K.; Rutqvist, J.; Tsang, C.; Jing, L. Stress-dependent permeability of fractured rock masses: A numerical study. Int. J. Rock Mech. Min. Sci. 2004, 41, 1191-1210. [CrossRef]

46. Baghbanan, A.; Jing, L. Stress effects on permeability in a fractured rock mass with correlated fracture length and aperture. Int. J. Rock Mech. Min. Sci. 2008, 45, 1320-1334. [CrossRef]

47. Saeidi, O.; Stille, H.; Torabi, S.R. Numerical and analytical analyses of the effects of different joint and grout properties on the rock mass groutability. Tunn. Undergr. Space Technol. 2013, 38, 11-25. [CrossRef]

48. Huang, D.; Cen, D.; Ma, G.; Huang, R. Step-path failure of rock slopes with intermittent joints. Landslides 2015, 12, 911-926. [CrossRef]

49. Huang, D.; Song, Y.; Cen, D.; Fu, G. Numerical modeling of earthquake-induced landslide using an improved discontinuous deformation analysis considering dynamic friction degradation of joints. Rock Mech. Rock Eng. 2016, 49, 4767-4786. [CrossRef]

50. Ren, H.; Zhuang, X.; Rabczuk, T. Dual-horizon peridynamics: A stable solution to varying horizons. Comput. Meth. Appl. Mech. Eng. 2017, 318, 762-782. [CrossRef]

51. Ren, H.; Zhuang, X.; Cai, Y.; Rabczuk, T. Dual-horizon peridynamics. Int. J. Numer. Methods Eng. 2016, 108, 1451-1476. [CrossRef]

52. Rabczuk, T.; Zi, G.; Bordas, S.; Nguyen-Xuan, H. A simple and robust three-dimensional cracking-particle method without enrichment. Comput. Methods Appl. Mech. Eng. 2010, 199, 2437-2455. [CrossRef]

53. Rabczuk, T.; Belytschko, T. Cracking particles: A simplified meshfree method for arbitrary evolving cracks. Int. J. Numer. Meth. Eng. 2004, 61, 2316-2343. [CrossRef]

54. Han, F.; Lubineau, G.; Azdoud, Y. Adaptive coupling between damage mechanics and peridynamics: A route for objective simulation of material degradation up to complete failure. J. Mech. Phys. Solids 2016, 94, 453-472. [CrossRef]

55. Han, F.; Lubineau, G.; Azdoud, Y.; Askari, A. A morphing approach to couple state-based peridynamics with classical continuum mechanics. Comput. Methods Appl. Mech. Eng. 2016, 301, 336-358. [CrossRef]

56. Zhang, Y.; Pichler, C.; Yuan, Y.; Zeiml, M.; Lackner, R. Micromechanics-based multifield framework for early-age concrete. Eng. Struct. 2013, 47, 16-24. [CrossRef]

57. Zhang, Y.; Zeiml, M.; Pichler, C.; Lackner, R. Model-based risk assessment of concrete spalling in tunnel linings under fire loading. Eng. Struct. 2014, 77, 207-215. [CrossRef]

58. Zhang, Y.; Zeiml, M.; Maier, M.; Yuan, Y.; Lackner, R. Fast assessing spalling risk of tunnel linings under RABT fire: From a coupled thermo-hydro-chemo-mechanical model towards an estimation method. Eng. Struct. 2017, 142, 1-19. [CrossRef]

59. Yang, M.; Yue, Z.; Lee, P.K.; Su, B.; Tham, L. Prediction of grout penetration in fractured rocks by numerical simulation. Can. Geotech. J. 2002, 39, 1384-1394. [CrossRef]

60. Hässler, L.; Håkansson, U.; Stille, H. Computer-simulated flow of grouts in jointed rock. Tunn. Undergr. Space Technol. 1992, 7, 441-446. [CrossRef]

61. Rahmani, H. Estimation of Grout Distribution in a Fractured Rock By Numerical Modeling. Ph.D. Thesis, University of British Columbia, Vancouver, BC, Canada, 2009.

62. Fidelibus, C.; Lenti, V. The propagation of grout in pipe networks. Comput. Geosci. 2012, 45, 331-336. [CrossRef]

63. Cacas, M.-C.; Ledoux, E.; Marsily, G.D.; Tillie, B.; Barbreau, A.; Durand, E.; Feuga, B.; Peaudecerf, P. Modeling fracture flow with a stochastic discrete fracture network: Calibration and validation: 1 . the flow model. Water Resour. Res. 1990, 26, 479-489. [CrossRef]

64. Dershowitz, W.; Einstein, H. Characterizing rock joint geometry with joint system models. Rock Mech. Rock Eng. 1988, 21, 21-51. [CrossRef]

65. Ma, G.; Wang, H.; Fan, L.; Wang, B. Simulation of two-phase flow in horizontal fracture networks with numerical manifold method. Adv. Water Resour. 2017, 108, 293-309. [CrossRef]

66. Ren, F.; Ma, G.; Fu, G.; Zhang, K. Investigation of the permeability anisotropy of $2 \mathrm{~d}$ fractured rock masses. Eng. Geol. 2015, 196, 171-182. [CrossRef]

67. Ren, F.; Ma, G.; Wang, Y.; Fan, L. Pipe network model for unconfined seepage analysis in fractured rock masses. Int. J. Rock Mech. Min. Sci. 2016, 88, 183-196. [CrossRef] 
68. Ren, F.; Ma, G.; Wang, Y.; Li, T.; Zhu, H. Unified pipe network method for simulation of water flow in fractured porous rock. J. Hydrol. 2017, 547, 80-96. [CrossRef]

69. Ren, F.; Ma, G.; Wang, Y.; Fan, L.; Zhu, H. Two-phase flow pipe network method for simulation of CO2 sequestration in fractured saline aquifers. Int. J. Rock Mech. Min. Sci. 2017, 98, 39-53. [CrossRef]

70. Nikolić, M.; Karavelić, E.; Ibrahimbegovic, A.; Miščević, P. Lattice element models and their peculiarities. Arch. Comput. Methods Eng. 2018, 25, 753-784. [CrossRef]

71. Grassl, P. A lattice approach to model flow in cracked concrete. Cement Concr. Compos. 2009, 31, 454-460. [CrossRef]

72. Nikolić, M.; Do, X.N.; Ibrahimbegovic, A.; Nikolić, Ż. Crack propagation in dynamics by embedded strong discontinuity approach: Enhanced solid versus discrete lattice model. Comput. Methods Appl. Mech. Eng. 2018, 340, 480-499.

73. Kazemian, S.; Prasad, A.; Huat, B.; Bazaz, J.B.; Mohammed, T.; Aziz, F.A. Effect of aggressive ph media on peat treated by cement and sodium silicate grout. J. Central South Univ. Technol. 2011, 18, 840-847. [CrossRef]

74. Kazemian, S.; Prasad, A.; Huat, B.B.; Ghiasi, V.; Ghareh, S. Effects of cement-sodium silicate system grout on tropical organic soils. Arab. J. Sci. Eng. 2012, 37, 2137-2148 [CrossRef]

75. Porcino, D.; Marcianò, V.; Granata, R. Static and dynamic properties of a lightly cemented silicate-grouted sand. Can. Geotech. J. 2012, 49,1117-1133. [CrossRef]

76. Sun, Z.; Li, S.; Liu, R.; Zhang, Q.; Zhang, L.; Zheng, Z. Fracture defusing mechanism and pressure characteristic tests of rapid setting cement-based grouts. Yantu Lixue (Rock Soil Mech.) 2014, 35, 2219-2225. (In chinese)

77. Zhang, Q.; Zhang, L.; Liu, R.; Li, S.; Zhang, Q. Grouting mechanism of quick setting slurry in rock fissure with consideration of viscosity variation with space. Tunnel. Underg. Space Technol. 2017, 70, 262-273. [CrossRef]

78. Mohajerani, S.; Baghbanan, A.; Bagherpour, R.; Hashemolhosseini, H. Grout penetration in fractured rock mass using a new developed explicit algorithm. Int. J. Rock Mech. Mining Sci. 2015, 80, 412-417. [CrossRef]

79. Ruan, W. Research on diffusion of grouting and basic properties of grouts. J. Geotech. Eng. 2005, 27, 69-73. (In Chinese)

80. Bear, J. Dynamics of Fluids in Porous Media (Dover Civil and Mechanical Engineering); Courier Corporation: ChelmsfordNorth Chelmsford, MA, USA, 1988; ISBN 978-0486656755.

81. Bear, J. Hydraulics of Groundwater (Dover Books on Engineering); Courier Corporation: ChelmsfordNorth Chelmsford, MA, USA, 2007; ISBN 978-0486453552.

82. Li, S.; Han, W.; Zhang, Q.; Liu, R.; Weng, X. Research on time-dependent behavior of viscosity of fast curing grouts in underground construction grouting. Chin. J. Rock Mech. Eng. 2013, 32, 1-7.

83. Wang, Y.; Ma, G.; Ren, F.; Li, T. A constrained delaunay discretization method for adaptively meshing highly discontinuous geological media. Comput. Geosci. 2017, 109, 134-148. [CrossRef]

84. Gustafson, G.; Stille, H. Stop criteria for cement grouting. Felsbau: Zeitschrift für Geomechanik und Ingenieurgeologie im Bauwesen und Bergbau 2005, 25, 62-68.

85. Liu, R. Study on Diffusion and Plugging Mechanism of Quick Setting Cement Based Slurry in Underground Dynamic Water Grouting and Its Application; Shandong University: Jinan, China, 2012, pp. 84-86.

86. Bandis, S.; Lumsden, A.; Barton, N. Fundamentals of rock joint deformation. Int. J. Rock Mech. Min. Sci. Geomech. Abstr. 1983, 20, 249-268. [CrossRef]

(C) 2018 by the authors. Licensee MDPI, Basel, Switzerland. This article is an open access article distributed under the terms and conditions of the Creative Commons Attribution (CC BY) license (http:/ / creativecommons.org/licenses/by/4.0/). 